\title{
MAL MEDIS DI MAKASSAR DENGAN PENDEKATAN BANGUNAN SEHAT
}

\author{
Nurpuspitasari $^{1}$, Taufik $\operatorname{Arfan}^{2}$, Mutmainnah $^{3}$ \\ Jurusan Arsitektur Fakultas Sains \& Teknologi UIN Alauddin Makassar \\ E-mail; meonk.itha@gmail.com, taufik.arfan@gmail.com, mutmainnah_sr@yahoo.com
}

\begin{abstract}
These planning and designing are aimed to design Medical Mall in Makassar with healthy building approach, although in macro such as deciding the location and footprint, and also in micro such as deciding the form and its appearance, program, measuring rooms and relating each rooms, structure, material, until its equipments. The method which is used is Descriptive, the data comes from secondary data, those are literature study through books, short papers, references, standard, internet and others written sources that is related with planning and designing Medical mall in Makassar with healthy building approach. The results of these designing are creating a place in servicing health and others facilities supporting medical health in a integrated building, that is based comfortable and save environment fulfill requirements of physiological, psychological and free from spreading diseases.
\end{abstract}

Keywords: Mall, Medical, Health.

\footnotetext{
${ }^{1}$ Alumni Jurusan Teknik Arsitektur UIN Alauddin Makassar Angkatan 2008

${ }^{2}$ Dosen Jurusan Teknik Arsitektur UIN Alauddin Makassar

${ }^{3}$ Dosen Jurusan Teknik Arsitektur UIN Alauddin Makassar
} 


\section{PENDAHULUAN}

\section{Latar Belakang}

Manusia modern saat ini selalu berusaha agar tetap tampil sehat dan bugar. Hal ini mengakibatkan kebutuhan dan tuntutan masyarakat terhadap pelayanan kesehatan yang berkualitas menjadi salah satu kebutuhan dasar, dimana masyarakat umum mulai mempunyai keyakinan yang besar bahwa kesehatan dan pelayanan kesehatan merupakan hak dasar, bukan sekedar fasilitas untuk sekelompok orang tertentu.

Selain kesadaran manusia itu sendiri untuk menjaga kesehatan, Allah SWT juga telah memerintahkan manusia agar segera memeriksakan kesehatannya dengan cara berobat pada saat ditimpa penyakit, hal ini dijelaskan pada Hadist Riwayat Abu Daud dan At-Tirmidzi dari sahabat Nabi Usamah bin Syuraik.

Konsep Mal Medis ini merupakan inovasi baru yang menarik di dunia kesehatan. Pembangunan Mal Medis ini akan menggunakan konsep bangunan sehat. Sebuah bangunan yang sehat didasarkan pada pemenuhan beberapa persyaratan. Untuk setiap bangunan, desain dan konstruksi perlu diperhatikan untuk keselamatan dasar penghuninya, namun hal ini tidak cukup untuk menjamin kualitas lingkungan di dalam ruangan untuk penghuninya. Ada sejumlah faktor lain yang mempengaruhi kesejahteraan penghuninya baik secara langsung maupun tidak langsung. Faktor yang berkontribusi terhadap kesehatan bangunan yang kompleks, dengan koneksi ke beberapa bidang, dintaranya: pembangunan bangunan berkelanjutan, peran dari penghuni terhadap lingkungan di dalam ruangan, dan penggunaan bahan bangunan yang berfokus pada kontrol kelembaban dan jamur. Ketiga faktor ini penting, karena dapat mengatasi masalah desain pada bangunan.

Mal Medis dengan konsep bangunan sehat diharapkan dapat menjadi suatu wadah pelayanan kesehatan dan berbagai fasilitas penunjang medis yang disatukan dalam satu atap terpadu, yang berbasis kenyamanan dan keamanan lingkungan yang memenuhi persyaratan fisiologis, psikologis, dan bebas dari penularan penyakit dengan tipologi masyarakat perkotaan, dikembangkan lebih jauh menjadi Mal Medis yang berwawasan kesehatan, baik dari segi fungsi maupun kualitas bangunannya dan dapat menjadi kekuatan untuk mendukung peningkatan mutu pelayanan kesehatan di kota Makassar.

\section{RUANG LINGKUP PEMBAHASAN}

\section{Lingkup Pembahasan}

Lingkup pembahasan dibatasi pada pemecahan permasalahan yang berkaitan dengan perencanaan dan perancangan sebuah bangunan Mal Medis sebagai pusat jasa rawat jalan, kebugaran, kecantikan, penjualan obat-obatan, makanan kesehatan, alat-alat kesehatan dan kebugaran, dan pusat informasi medis yang disatukan dalam satu atap terpadu, yang juga dilengkapi fasilitas penunjang lainnya, ditinjau dari disiplin ilmu arsitektur dan tidak terlepas dari unsur-unsur pendukung sebuah bangunan sehat yang dapat menciptakan lingkungan yang sehat, alami dan nyaman sehingga mendukung fungsi bangunan sebagai tempat pelayanan kesehatan.

\section{METODE PEMBAHASAN}

Pembahasan dilakukan dengan metode deskriptif, yaitu menguraikan, menjabarkan, dan menjelaskan tentang faktor-faktor yang dibutuhkan dalam perencanaan 
dan faktor yang menentukan desain. Berdasarkan hal tersebut, akan diadakan pengumpulan data yang diperlukan kemudian dijabarkan dan dianalisa untuk menghasilkan kesimpulan, batasan dan anggapan yang akan digunakan sebagai dasar dari perencanaan dan perancangan Mal Medis di Makassar dengan pendekatan bangunan sehat.

Data yang diperoleh berasal dari Data sekunder, yaitu studi literatur melalui buku, makalah, referensi, standar, internet dan sumber-sumber tertulis yang berhubungan dengan perencanaan dan perancangan Mal Medis di Makassar dengan pendekatan bangunan sehat.

\section{KONSEP DAN STRATEGI PENDEKATAN BANGUNAN SEHAT}

\section{Konsep Bangunan Sehat}

Konsep bangunan sehat muncul dari istilah 'Rumah Sehat' dan 'Pemukiman Sehat' yang kemudian dibuat menjadi istilah yang umum yaitu 'Bangunan Sehat', dimana pengertian rumah sehat menurut American Public Health Association (APHA) rumah sehat dirumuskan sebagai suatu tempat untuk tinggal secara permanen, berfungsi sebagai tempat untuk bermukim, beristirahat, berekreasi (bersantai) dan sebagai tempat berlindung dari pengaruh lingkungan yang memenuhi persyaratan fisiologis, psikologis, dan bebas dari penularan penyakit.

Bangunan yang sehat harus memperhatikan kesehatan manusia dalam lingkungan yang dibangun, sehingga dapat meminimalkan penyebab meningkatnya masalah kesehatan, seperti masalah pernapasan, kelelahan, stres, depresi dan lainnya yang berhubungan dengan penurunan kesehatan kualitas hidup.

\section{Strategi Pendekatan Bangunan Sehat}

Berikut beberapa komponen bangunan sehat yang akan diaplikasikan pada perencanaan dan perancangan bangunan Mal Medis.

1. Pemilihan dan pengolahan tapak

2. Memiliki kualitas udara yang baik

3. Memiliki control pencahayaan yang baik

4. Menggunakan material yang sehat

5. Akses ke lingkungan alam dengan memanfaatkan ruang terbuka hijau

6. Pengelolaan limbah medis

\section{HASIL PERANCANGAN}

\section{Lokasi Perancangan}

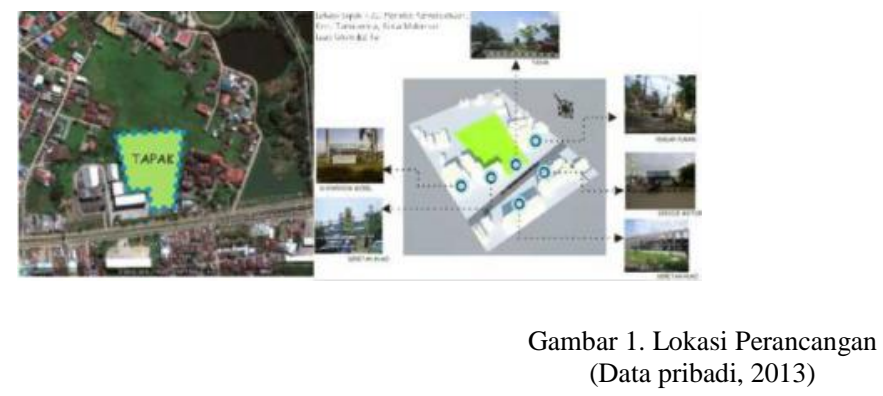




\section{Konsep Pengolahan Tapak}

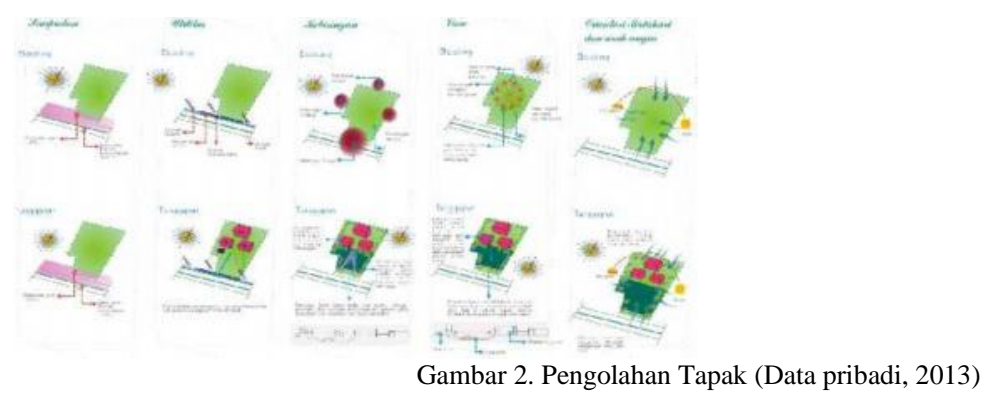

\section{Site Plan}

Nama proyek : Mal Medis di Makassar dengan Pendekatan Bangunan Sehat Lokasi Proyek : Jl. Perintis Kemerdekaan

Luasan Lahan : \pm 2 ha

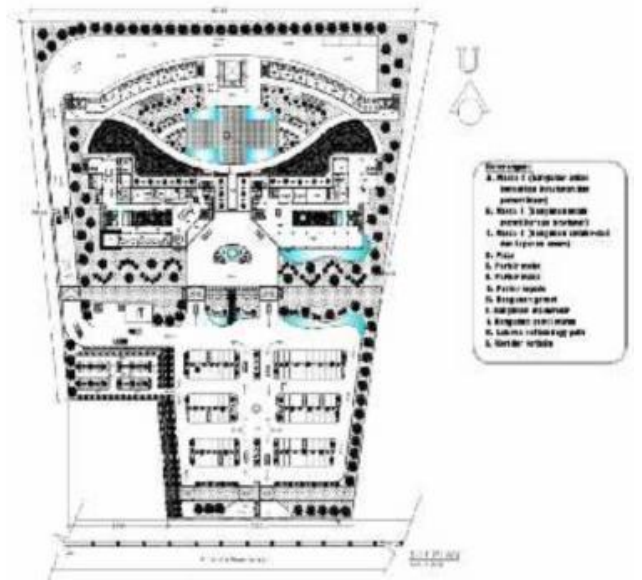

\section{Transformasi Desain}
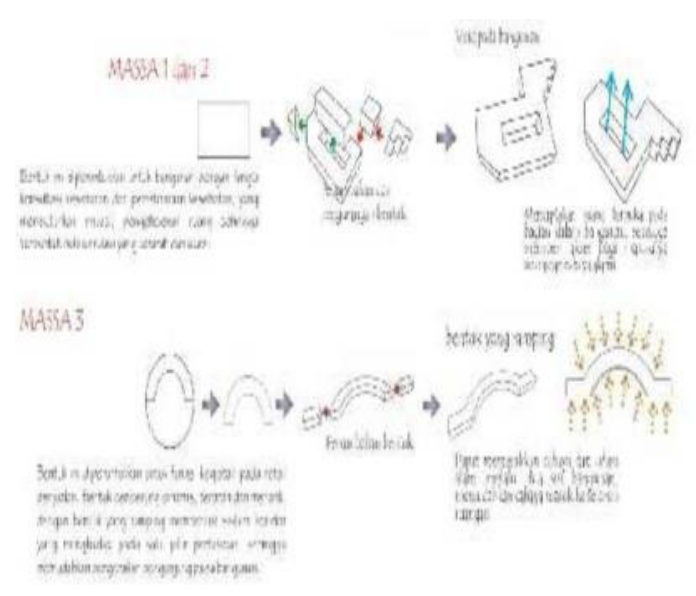

Gambar 4. Konsep Transformasi bentuk bangunan (Data pribadi, 2013) 
Nature

National Academic Journal of Architecture

\section{Konsep Layout Ruang}

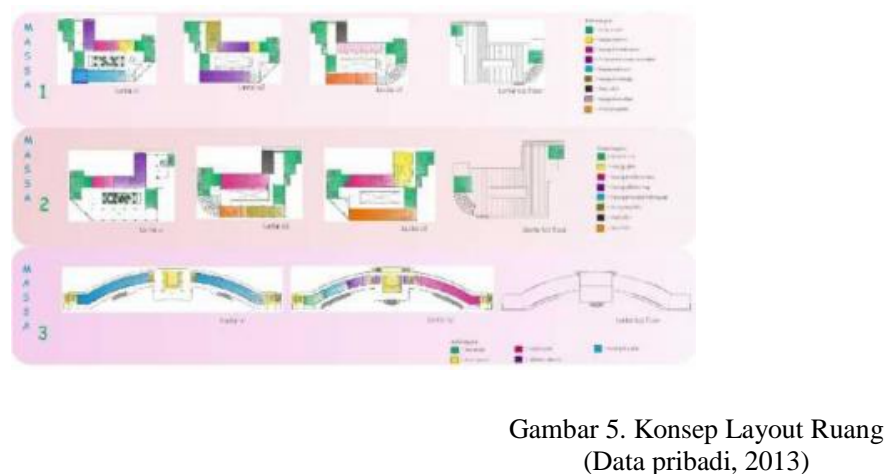
(Data pribadi, 2013)

\section{Material}
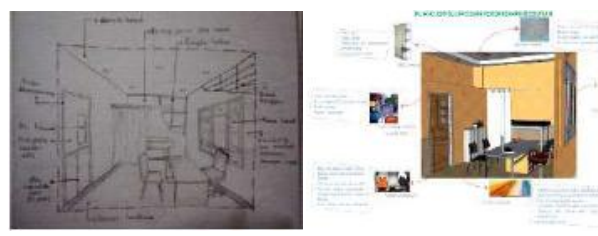

Gambar 6. Ruang

konsultasi dan

pemeriksaan

(Data pribadi, 2013)
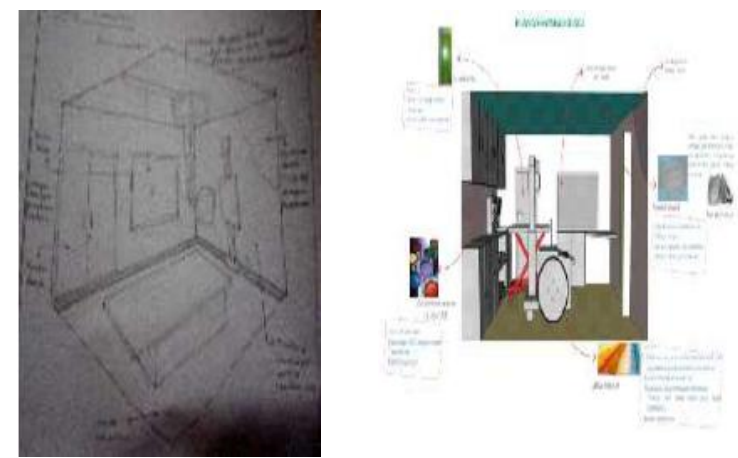

Gambar 7. Ruang radiologi
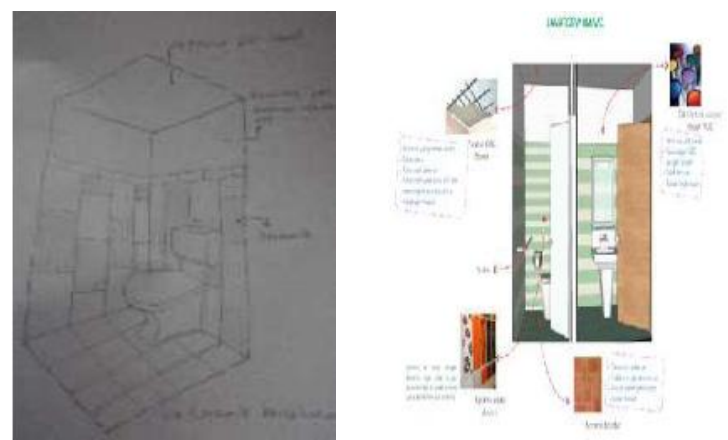

Gambar 8. Retail

(Data pribadi, 2013)
Gambar 9. Lavatory

(Data pribadi, 2013) 
Nature

National Academic Journal of Architecture

\section{Struktur}

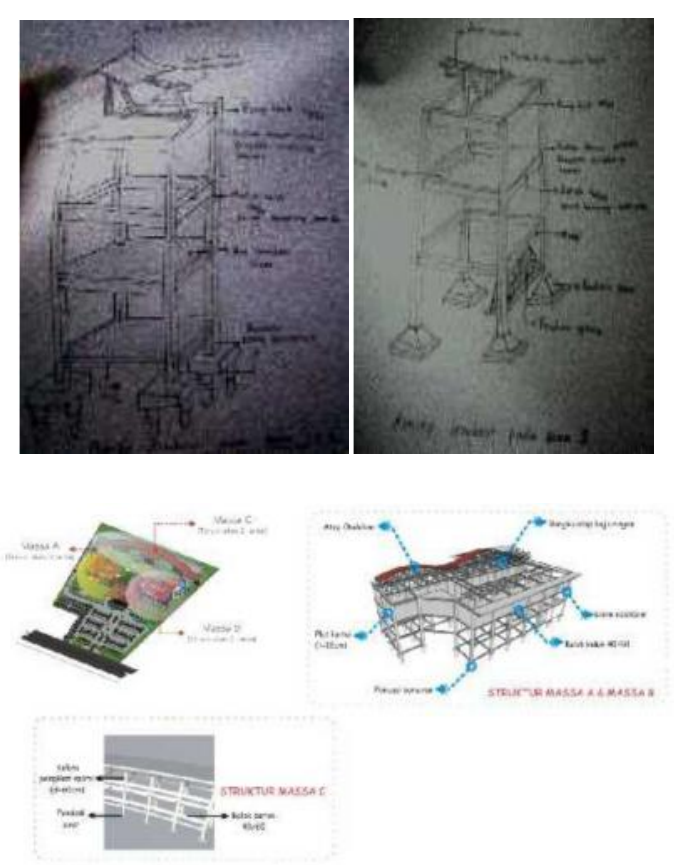

Gambar 10. Konsep struktur (Data pribadi, 2013)

\section{Tema Bangunan Sehat}

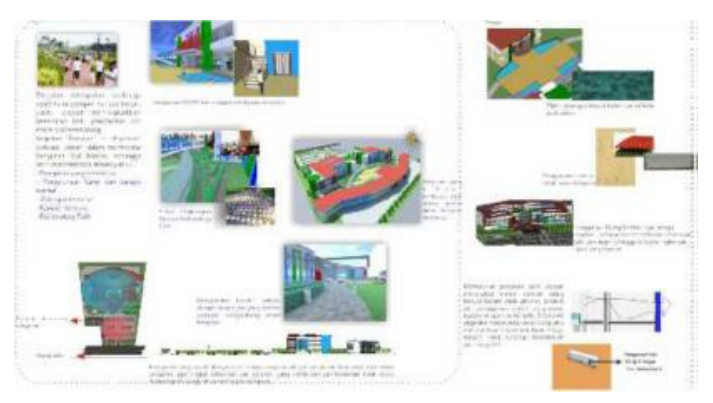

Gambar 11. Konsep struktur (Data pribadi, 2013)

\section{Desain Akhir}

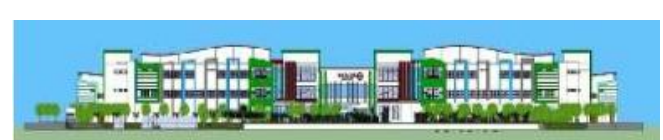

Gambar 12. Tampak selatan (Data pribadi, 2013)

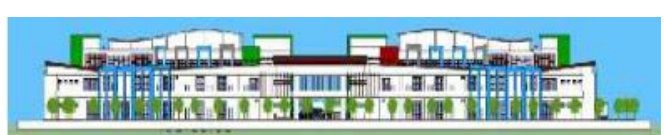

Gambar 13. Tampak utara (Data pribadi, 2013) 


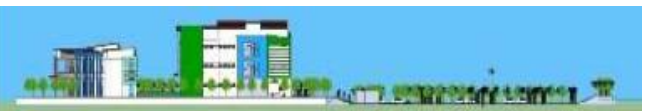

Gambar 14. Tampak barat (Data pribadi, 2013)

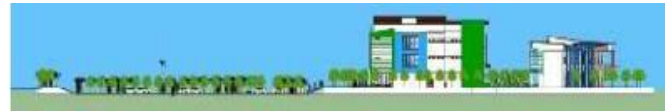

Gambar 15. Tampak timur (Data pribadi, 2013)

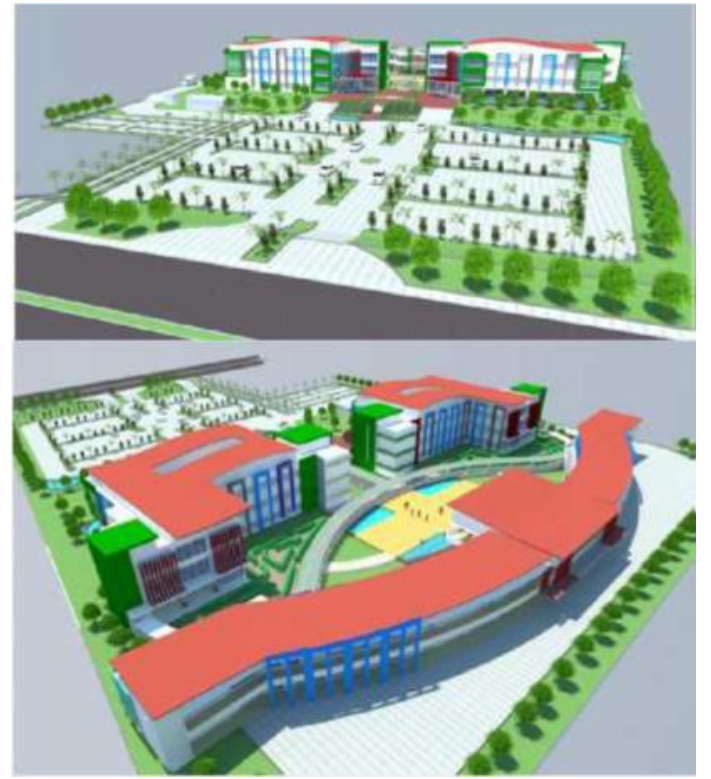

Gambar 16. Perspektif

(Data pribadi, 2013)

\section{DAFTAR PUSTAKA}

Hunter, Donald E. Medical Mall Planning Study.2007.New York: Hunter Interest.Inc Neufert, Ernest.1997. Data ArsitekJilid 1. Jakarta: Erlangga

Neufert, Ernest.2002.Data ArsitekJilid II. Jakarta:

ErlanggaAnonim.http://Jtpunimus-gdl-enakartik-5140-2-bab1.pdf, diakses tanggal 22 Juli2012

Anonim.http://Jtpunimus-gdl-vickynurp-5195-2-bab1.pdf, diakses tanggal 22 Juli2012 
Nature

National Academic Journal of Architecture 